DOI: http://dx.doi.org/10.20435/multi.v21i49.759

\title{
Hotel Gaspar no contexto patrimonial e identitário de Campo Grande, MS (1954-2014)
}

\author{
Gaspar Hotel in the equity and identity context of \\ Campo Grande, MS (1954-2014)
}

Elaine Cristina Paganotti Rezende ${ }^{1}$ Mário Márcio da Rocha Cabreira ${ }^{2}$ Maria Augusta de Castilho ${ }^{3}$

Mestre em Desenvolvimento Local. Docente na Universidade Católica Dom Bosco (UCDB). E-mail: elainepaganotti2011@hotmail.com

Mestrando em Desenvolvimento Local na Universidade Católica Dom Bosco (UCDB). Servidor da Universidade Federal de Mato Grosso do Sul. E-mail: rcabreira.mariomarcio@gmail.com

Pós-Doutorado em Linguística. Doutorado em Ciências Sociais

- História do Brasil. Professora no Curso de História e Coordenadora do Programa de Pós-Graduação em Desenvolvimento Local da Universidade Católica Dom Bosco (UCDB). E-mail: m.a.castilho@terra.com.br 


\section{RESUMO ABSTRACT}

Este artigo analisou o Hotel Gaspar no contexto patrimonial e identitário de Campo Grande-MS. Inicialmente, o texto apresenta a história da arte, os conceitos de memória e patrimônio cultural e, por fim, expõe os aspectos históricos do referido hotel. A metodologia utilizada quanto à abordagem foi qualitativa, com a alternativa para o método indutivo, e, no que se refere ao tipo de pesquisa, escolheu-se a exploratória e descritiva.

A coleta de dados se deu por meio de revisão bibliográfica e pesquisa de campo (entrevista semiestruturada). Conclui-se que o Hotel Gaspar faz parte do patrimônio histórico de Campo Grande/MS, da memória da cidade morena e de sua comunidade, com momentos e histórias vividas no passado, preservadas no presente, trabalhando para a conservação patrimonial e cultural da localidade.
This article analyzed the Hotel Gaspar in the equity and identity context of Campo Grande-MS. Initially, the text presents the history of art, the concepts of memory and cultural heritage, and finally presents the historical aspects of this hotel. The methodology used as the qualitative approach, as an alternative to inductive and, regarding the type of research, have chosen to descriptive and exploratory. The data collection was carried out through literature review and field research (semi-structured interview). It is concluded that the Hotel Gaspar is part of the historical heritage of Campo Grande / MS, the memory of the dark brown city and its community, with moments and stories lived in the past, preserved in the present, working for the patrimonial and cultural conservation of the locality.

\section{KEY WORDS}

memory

cultural heritage

Hotel Gaspar 


\section{INTRODUÇÃo}

O objetivo geral proposto pela presente pesquisa foi demonstrar a relevância do Hotel Gaspar no contexto patrimonial e identitário de Campo Grande, MS. Quanto à abordagem do estudo, foi qualitativa, que, segundo Marques et al. ( 2014), refere-se a dados que não podem ser matematizados, isto é, uma abordagem que permite uma visão de mundo, a qual busca explicar a realidade e compreendê-la a partir da revelação dos mapas mentais dos sujeitos, objeto da investigação.

Quanto ao método, usou-se o indutivo, visto que a pesquisa se inicia do particular para o geral. A base técnica insere-se na observação in loco, que consiste em ver, sentir e escutar. Já no que se refere aos procedimentos, a opção foi pelo método histórico, que, de acordo com Marques et al. (2014), tem a pretensão de pesquisar os acontecimentos e averiguar sua influência no mundo atual.

0 trabalho foi exploratório, com o intuito de obter mais informações sobre a temática em estudo, assim como sobre o objeto de pesquisa em estudo. É também descritivo, visto que busca descrever e caracterizar fenômenos e populações locais.

A coleta de dados se deu por meio de revisão bibliográfica, que, de acordo com Marques et al. (2014), é aquela cujos dados são secundários, obtidos em livros, revistas. Ainda se utilizou a pesquisa de campo na coleta de dados, visto que estes são obtidos diretamente na fonte, objeto de estudo.

Inicialmente, o texto apresenta conceitos de memória e patrimônio cultural, expondo aspectos históricos e relevantes do Hotel Gaspar para a cidade de Campo Grande, MS. 


\section{REFERENCIAL TEÓRICO}

Inicialmente, pondera-se relevante o conceito de memória que, segundo (TODOROW 2002, p.141 apud CASTILHO; SANTOS 2012 , p. 35) consideram que "a memória é a vida do passado no presente". De certa forma, as experiências e as histórias vividas no passado permanecem no presente, por meio da memória. Contudo, "na maior parte das vezes, lembrar não é reviver, mas refazer, reconstruir e repensar imagens de hoje, as experiências do passado" (BOSI, 1994, p. 55 apud CASTILHO; SANTOS 2012, p. 35).

Segundo Bosi (2003, p.36):

Pela memória, o passado não só vem à tona das águas presentes, misturando-se com as percepções imediatas, como também empurra 'descola' estas últimas, ocupando o espaço todo da consciência. A memória aparece como força subjetiva ao mesmo tempo profunda e ativa, latente e penetrante, oculta e invasora.

É a partir da memória que se mantém vivo o passado no presente. Nora (1993) faz uma distinção entre memória e história, sendo que a memória é compreendida como um fenômeno sempre atual via conexão vivida no presente/passado.

Cabe destacar, ainda, a relevância do conceito de patrimônio cultural. As discussões a respeito de conceitos sobre políticas direcionadas aos bens que fazem parte do patrimônio cultural de um povo remontam, mais individualmente, à Revolução Francesa (1789), época em que se desenvolveu com mais afinco a sensibilidade em relação aos monumentos dedicados a evocar a memória e evitar o esquecimento dos feitos do passado. A partir da Revolução Francesa, iniciam-se as primeiras ações políticas nesse sentido, com objetivo de conservar os bens que significavam a força, a nobreza da nação que os portava, entre as quais, uma administração incumbida de preparar as ferramentas jurídicas e técnicas para a preservação, assim como metodologias técnicas necessárias para a continuação e a restauração dos monumentos (CHOAY, 2001). 
Funari e Pelegrini (2006) evidenciam que, na Revolução Francesa, emergiu-se uma comissão para cuidar da preservação dos momentos nacionais e assim preservar os monumentos que representavam a nação francesa e sua cultura.

O Patrimônio cultural está relacionado à cultura do país e diz respeito à herança de uma cidade, um município ou país. É considerado um conjunto de práticas estabelecidas ao longo da história. Considera-se um bem coletivo, visto que pertence a todos os cidadãos (CASTILHO; SANTOS, 2012).

As autoras citadas afirmam, ainda, que o patrimônio cultural se refere aos bens materiais e imateriais, sendo que os bens materiais são constituídos com base no conhecimento, aclamado pela sociedade, assim como, dos meios, instrumentos e da criatividade que seus atores têm disponíveis. Contudo, os bens imateriais, chamados de cultura viva, são criados e recriados constantemente.

Considera-se o patrimônio cultural, com toda sua intensidade e complexidade, como um dos principais artefatos no processo de planejamento e ordenação da dinâmica de crescimento das cidades, como também um elemento estratégico na afirmação de identidade de grupos e comunidades (FONSECA, 1997).

No Brasil, o patrimônio cultural possui um viés antropológico, que envolve as expressões de todos os grupos e todas as camadas sociais, destacando em sua relevância as culturas tradicionais populares e indígenas (CAVALCANTI, 2008).

0 patrimônio é considerado um bem comum, coletivo; diante disso, é preciso definir suas regras e leis, seus limites físicos e conceituais. Nesse sentido, o estatuto ideológico do patrimônio e o Estado Nacional iniciam garantias específicas a sua preservação. O conceito de patrimônio foi ampliado para uma identidade nacional e contribuiu para a construção da consolidação dos estados contemporâneos (FONSECA, 1997). Contudo, o tombamento é considerado apenas como um dos meios legais de preservação, 
emergidos pelo Estado, com o objetivo de conservar a memória e os valores culturais (SOUZA FILHO, 1997).

Entretanto, para que haja patrimônio, impera que ele seja reconhecido, que tenha valor no âmbito das relações sociais e simbólicas, com valor e reconhecimento que são construídos ao redor do objetivo em si (POULOT, 2008 apud FERREIRA, 2006).

\section{HOTEL GASPAR}

Antônio Gaspar era comerciante. Veio para Campo Grande, vender dormentes que seriam utilizados na manutenção da ferrovia. Em seguida, montou um bar, na Rua 14 de Julho. Com visão de futuro, resolveu, em 1950, comprar um terreno na esquina da Avenida Mato Grosso com a Avenida Calógeras, com a ideia de, ali, construir o Hotel Gaspar (Fig. 1), que acabou por ser inaugurado em 26 de agosto de 1954, coincidindo com o aniversário da cidade.

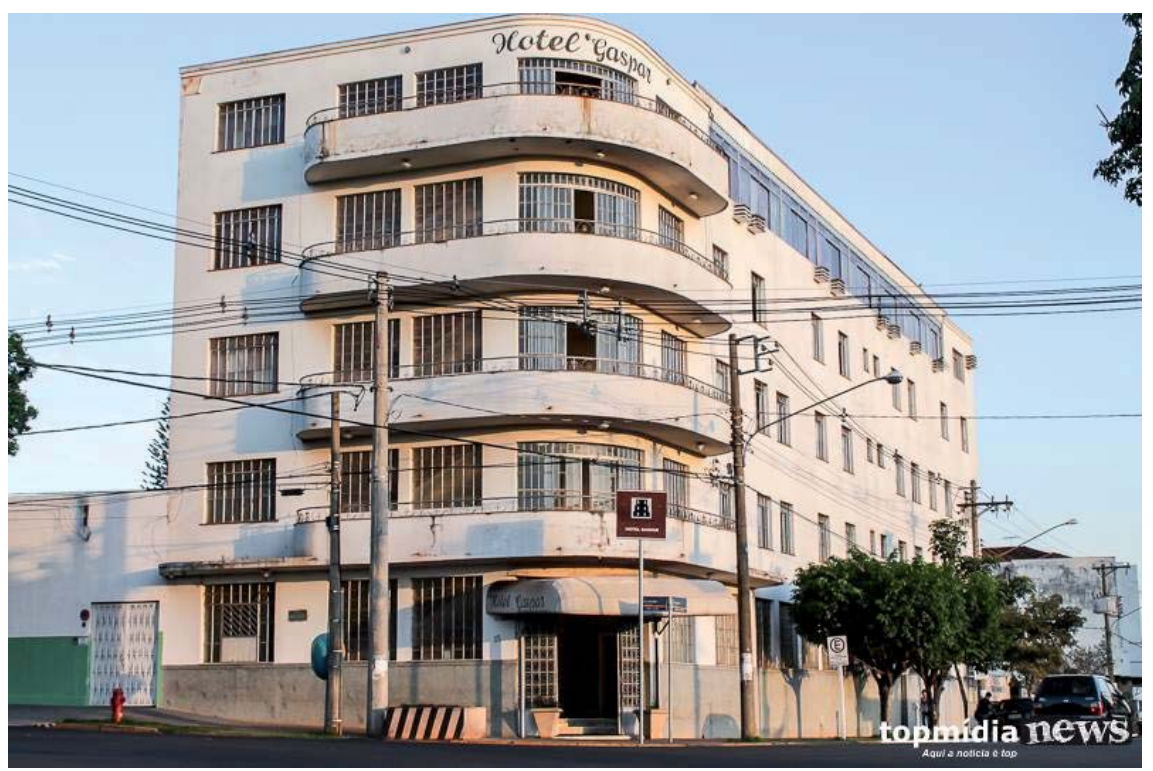

Figura 1 - Hotel Gaspar - Campo Grande, MS

Fonte: <http://www.topmidianews.com.br>. Acesso em: 3 fev. 2014. 
Christhian Gaspar ${ }^{1}$ (2014) lembra-se do avô afirmar que o trem era o principal meio de transporte para se chegar à cidade, e que o hotel era disputadíssimo.

Tanto que algumas pessoas pulavam o muro da ferrovia, para ter acesso mais rapidamente ao hotel, que se tornou uma referência na cidade. "Inclusive por algum tempo, a lavanderia do Hotel foi transformada em guichê para venda de passagens de ônibus municipais e interestaduais. (GASPAR, 2014).

Logo após o falecimento de seu avô, Antônio Gaspar, em 1989, a esposa dele, senhora Mariana Gaspar passou a conduziu os negócios do Hotel, até 1999. “Depois, minha avó arrendou o Hotel para os donos da padaria Espanhola, que ficava ao lado. Terminado esse período de arredamento, nós os netos, resolvemos retomar a administração" (GASPAR, 2014).

Christhian Gaspar, em 2014, completou 45 anos de idade. Ela é neta de Antônio Gaspar, responsável pela criação do Hotel Gaspar, localizado no complexo da Antiga Estação Ferroviária de Campo Grande, MS. O prédio, apesar de não ter sido ainda tombado, é considerado um patrimônio histórico e cultural da cidade. Construído em 1954, continua funcionando como hotel, mas permanece com sua estrutura original. 0 local foi e continua sendo um referencial na cidade, tendo acompanhado diversas etapas de seu crescimento e desenvolvimento.

Proprietária e gerente do Hotel Gaspar, Christhian Gaspar (2014) conta que era professora do Ensino Fundamental, mas que sempre se interessou por aspectos históricos e de preservação da memória, o que a motivou a deixar a carreira de professora, para se dedicar exclusivamente ao Hotel e à preservação desse patrimônio histórico de sua família e da cidade.

\footnotetext{
${ }^{1}$ As citações de Christhian Gaspar no presente estudo referem-se a entrevista realizada com a gerente do Hotel Gaspar, neta do fundador do referido hotel e concedida a Elaine Cristina Paganotti Rezende em maio de 2015.
} 
Ela assinala, ainda, que nunca recebeu incentivo algum do governo para preservar o local e que, também, nunca procurou ajuda oficial nesse sentido. “Campo Grande só há pouco tempo despertou seu olhar para o seu patrimônio histórico. Isso aqui tudo, por exemplo, estava perdido. Começou a mudar em 2004, quando o hotel fez 50 anos, e o então prefeito André Puccinelli, ampliou a Avenida Mato Grosso, trouxe a Feira Central para essa região, reestruturou a Esplanada dos Ferroviários e iniciou o processo de revitalização de todo esse complexo. Para o Hotel Gaspar, foi muito bom" (GASPAR, 2014). Também, informa que chegou a ser procurada pela prefeitura de Campo Grande, (não sabe precisar exatamente a data), a fim de discutir e iniciar o processo de tombamento do hotel. "Ficamos bem reticentes quanto a esse tombamento, por não saber exatamente que tipo de limitações isso acarretaria em nosso trabalho", relata a gerente do hotel.

Sobre o tombamento oficial do Hotel Gaspar como patrimônio histórico e cultural da cidade, Gaspar (2014) sente-se receosa em levar essa ideia adiante. "Não tenho noção exata do que isso representaria na rotina de funcionamento do hotel. Por enquanto, não temos essa intenção. Preservamos tudo, mais por opção nossa mesmo" (GASPAR, 2014).

Nesse diapasão, a gerente relembra que o ambiente na região era muito pesado, com a presença de marginais, consumidores de drogas, muitos mendigos e pedintes, e que esse cenário começou a mudar no final de 2004. Ela ainda assinala que "inclusive, o prefeito Nelson Trad Filho despachava, uma vez por semana, na casa da prefeitura instalada no complexo, em frente ao hotel. Antes disso, havia muita malandragem no entorno do prédio, e a gente não se sentia segura para trabalhar no local. Nesse aspecto, a revitalização do complexo ferroviário foi muito boa para o hotel".

Dimensiona-se que, apesar de seu caráter de patrimônio histórico e cultural da cidade, o hotel não integra oficialmente o Complexo Histórico da velha estação ferroviária - NOB. 
A equipe familiar responsável pela preservação e pelo funcionamento do Hotel Gaspar tem, além de Christhian Gaspar, sua irmã Ana Paula Gaspar Melin e o irmão Antônio José Gaspar Melin, todos netos do fundador. Além disso, o cunhado da gerente, César Braga, também atua no gerenciamento do local. Ao todo, são 11 pessoas que compõem a equipe de trabalho.

$\mathrm{Na}$ visita in loco, identificou-se que o hotel tem 60 apartamentos ativos, de um total de 84 existentes, e que os outros 24, por não terem janelas, em razão de terem ficado isolados nos corredores, são usados atualmente, como almoxarifado e dependências administrativas da empresa.

A gerente explicou, também, que algumas mudanças foram feitas no projeto original, porque, por questões legais, algumas adaptações foram necessárias, mas que, no geral, as características originais foram conservadas, como, por exemplo: pisos, lustres, guarda-roupas, azulejos de banheiro, camas e mobiliário em geral, inclusive louças de copa e cozinha.

Identificou-se que o hotel conserva os elevadores originais, com paredes internas azuis. A pintura externa e externa do prédio é da cor branca, a mesma da época da inauguração, há 60 anos. "Recentemente, quando fomos renovar a pintura externa e interna do prédio, recebemos a visita de técnicos do Instituto do Patrimônio Histórico Artístico Nacional (IPHAN), com sugestões de cores que deveriam ser usadas. Estavam mesmo preocupados com a descaracterização do prédio. Entretanto, sempre foi branco, e pretendemos que continue assim", relembra a gerente.

O hotel não tem verba específica para conservação do patrimônio nem conta com um programa específico de divulgação dessa linha de funcionamento entre os hóspedes. "Nosso faturamento é sazonal, e nossa receita é flutuante, há épocas de maior e de menor frequência de hóspedes. Por isso, alguns reparos e algumas manutenções são sempre urgentes, como: troca de 
chuveiros, válvulas de sanitários, alguns canos etc. Mas, no geral, procuramos manter a estrutura original intacta" (GASPAR, 2014).

No olhar da administradora do hotel, existe uma relação diferenciada com seus hóspedes, desde a época de seus avôs, pois tem clientes que são hóspedes há mais de 30 anos. Alguns, inclusive, residem no hotel. Isso cria uma relação de proximidade, de pessoalidade da equipe do hotel com os clientes. São senhores e senhoras já de idade avançada, que acabam se tornando parte da família hoteleira na localidade.

Um dos grandes orgulhos da administradora é o fato de o Hotel Gaspar ter sediado a locação do filme "Cabeça a Prêmio", do diretor Marco Rica, tendo no elenco Alice Braga e Eduardo Moscovis e outros ${ }^{2}$. Muitos ensaios fotográficos para revistas de moda também utilizam o hotel como cenário. "Isso trouxe maior visibilidade ao hotel e marcou definitivamente seu valor histórico e cultural nessa região da cidade", finaliza a gerente.

Entre os hóspedes ilustres do Hotel Gaspar, estão os ex-presidentes da república do Brasil Emílio Garrastazu Médici e Jânio Quadros, o ex-senador Filinto Müller, além de artistas, como Cauby Peixoto e Ângela Maria. Toda essa história está registrada em fotos e recortes de jornais, emoldurados e afixados nas paredes do hall de entrada e corredores do Hotel Gaspar.

\section{CONSIDERAÇÕES FINAIS}

Nota-se que preservar o patrimônio cultural de um país, estado ou de uma cidade é extremamente relevante para manter viva a memória de uma sociedade, comunidade ou indivíduo. Sejam individuais ou coletivas, memórias devem manter o passado vivo no presente, sendo uma forma de conservar elementos patrimoniais (materiais ou imateriais). É uma forma de manter objetos,

${ }^{2}<$ http://youtu.be/gScDQxzcEvw/2014>. 
momentos e experiências vividas em um passado e que podem e devem ser relembradas no presente e futuro. A conservação do patrimônio começa a partir da memória, do reconhecimento e valor dado ao patrimônio em si, seja um bem material ou não.

O Hotel Gaspar faz parte do patrimônio cultural de Campo Grande, possui bens materiais e imateriais com significados, reconhecidos como identidade cultural, faz parte da memória dos fundadores, hóspedes e da sociedade campo-grandense. A implantação do hotel, com a vinda da ferrovia (NOB) a Campo Grande, não mereceu, ainda, por parte das autoridades, seu tombamento, mas todas as iniciativas de preservação foram realizadas, exclusivamente, pelos familiares descendentes da família Gaspar, que reconhecem a importância do hotel como um patrimônio histórico e cultural de Campo Grande-MS. Construído em 1954, permanece com sua estrutura original e é um referencial para a capital sul-mato-grossense, visto que acompanhou diversas etapas de seu crescimento e desenvolvimento.

\section{REFERÊNCIAS}

BOSI, E. O tempo vivo da memória: ensaios de psicologia social. São Paulo: Ateliê, 2003.

CAVALCANTI, M. L. V. de C.; FONSECA, M. C. L. Patrimônio imaterial no Brasil: legislação e políticas estaduais. Brasília: UNESCO, 2008.

CHOAY, F. A alegoria do patrimônio. São Paulo: Estação Liberdade, 2001.

FERREIRA, M. L. M. Patrimônio: discutindo alguns conceitos. In: Diálogos, Maringá, PR, v. 10, n. 3, p. 79-88, 2006.

FONSECA, M. C. L. O patrimônio em processo: trajetória da política federal de preservação no Brasil. Rio de Janeiro: UFRJ/Iphan, 1997.

FUNARI, P. P. A.; PELEGRINI, S. Patrimônio histórico e cultural. Rio de Janeiro: Jorge Zahar, 2006.

GASPAR, Christhian. Informações sobre o Hotel Gaspar. fev. 2014. Gravação em celular (60 min.). 
MARQUES, H. R. M. et al. Metodologia da pesquisa e do trabalho científico. 4. ed. revisada e atualizada. Campo Grande, MS: UCDB, 2014.

NORA, P. Entre memória e história: a problemática dos lugares. Projeto História, Revista do Programa de Estudos Pós-graduados em História/ Departamento de História, PUC, SP, São Paulo, n. 10, p. 7-28, 1993.

RICA, M. Cabeça a prêmio. Disponível em: <http://youtu.be/ gScDQxzcEvw>. Acesso em: 30 out. 2014.

SANTOS, M. C. L. F.; CASTILHO, M. A. Rota do trem do pantanal: diálogo entre patrimônio e desenvolvimento local. Campo Grande, MS: Life, 2012.

SOUZA FILHO, C. F. M. Bens culturais e proteção jurídica. Porto Alegre, RS: Unidade Editorial, 1997. 